\title{
ANALYSIS OF THE PRESENT SITUATION OF RESPONSE CONTROL SYSTEMS IN JAPAN BASED ON BUILDING SURVEY DATABASE
}

\author{
Haruyuki KITAMURA ${ }^{1}$, Yoshihisa KITAMURA ${ }^{2}$, Masaru ITO $^{3}$, and Mitsuo SAKAMOTO ${ }^{4}$ \\ ${ }^{1}$ Member of JAEE, Professor, Department of Architecture, Faculty of Science and Engineering, \\ Tokyo University of Science, Tokyo Japan, kita-h@rs.noda.tus.ac.jp \\ ${ }^{2}$ Shimizu Corporation Ltd. \\ ${ }^{3}$ Nihon Sekkei,Inc. \\ ${ }^{4}$ Kajima Corporation Ltd.
}

\begin{abstract}
Twenty years have passed since response control systems, which reduce structural damages caused by earthquakes or strong winds, started to be used in actual buildings. JSCA conducted a survey of response-controlled buildings on design offices and construction companies, and made a database. Using this database a classification of the number of the buildings that use response control systems by the year of construction, the purposes of the building, and the type of mechanism device is performed. Also, the distribution of the applied damping forces and their response reduction efficiency are analyzed. Discussions of these analyses and of the present response control systems situation in Japan are finally reported in this paper.
\end{abstract}

Key Words: Response Controlled Buildings, Energy Absorption Systems, Additional Mass Systems

\section{INTRODUCTION}

Twenty years have passed since response control systems, seismic isolated systems started to be used in real buildings to reduce damages due to earthquakes and strong winds. At present they are applied in different type of structures, scales and heights for new buildings and for earthquake resistant retrofit. This report deals with the evaluation done for the response controlled buildings at present in Japan using the JSCA (Japan Structural Engineer and Consultant Association) database developed during August to November $2002^{1)}$.

\section{CLASSIFICATION OF RESPONSE CONTROLLED BUILDINGS}

As shown in Table 1, the response control systems are divided in two: energy absorption systems and additional mass systems. Besides, these are further classified according to the characteristics of the element and system: hysteresis damping type, viscous damping type, passive mass damper, active mass damper. 
Table 1 Response Control Structures Classification

\begin{tabular}{|c|c|l|}
\hline Systems & Types & \multicolumn{1}{|c|}{ Devices } \\
\hline \multirow{2}{*}{$\begin{array}{c}\text { Energy Absorption } \\
\text { Systems }\end{array}$} & $\begin{array}{c}\text { Hysteresis Damping Type } \\
\text { (HD) }\end{array}$ & $\begin{array}{l}\text { Steel Hysteresis Damper, } \\
\text { Lead Damper, Friction Damper }\end{array}$ \\
\cline { 2 - 3 } (VD) & $\begin{array}{c}\text { Viscous Damping Type } \\
\text { Additional Mass } \\
\text { Systems }\end{array}$ & $\begin{array}{l}\text { Oil Damper, Viscous Damper, } \\
\text { Visco-Elastic Damper }\end{array}$ \\
\cline { 2 - 3 } & Passive Mass Damper & $\begin{array}{l}\text { Tuned Mass Damper (TMD), } \\
\text { Tuned Liquid Damper (TLD) }\end{array}$ \\
\hline \multirow{2}{*}{$\begin{array}{c}\text { Active Mass Damper } \\
\text { (Vtive Mass Damper (AMD), } \\
\text { Hybrid Mass Damper (HMD) }\end{array}$} \\
\hline
\end{tabular}

\section{SUMMARY OF THE INVESTIGATION}

The investigation is summarized in Table 2. Investigation sheets were developed for energy absorption systems, additional mass systems, earthquake resistant retrofits respectively, and were handled to response control systems design experts, mainly members of JSCA. A database with a total of 494 cases was developed using the replies from 16 design companies and 21 construction companies.

Table 2 Outline of the Investigation Items

\begin{tabular}{|l|l|}
\hline Building Outline & $\begin{array}{l}\text { Building name, Design year, Completion date, Location, Building use, } \\
\text { Structure type, Designer, Constructor, Number of floors, Total building } \\
\text { height, Total building area, Typical floor area, Natural period, Base shear } \\
\text { coefficient, Seismic zone coefficient, Total building weight }\end{array}$ \\
\hline $\begin{array}{l}\text { Building Outline } \\
\text { (Retrofit) }\end{array}$ & $\begin{array}{l}\text { Year of retrofit, Is value, Earthquake resistant reinforcement, Device set up } \\
\text { frames }\end{array}$ \\
\hline $\begin{array}{l}\text { Control Systems } \\
\text { Outline }\end{array}$ & $\begin{array}{l}\text { Control system used, Maker, Device set up location, Device set up } \\
\text { members, Number of devices }\end{array}$ \\
\hline $\begin{array}{l}\text { Control Systems Details } \\
\text { (Energy Absorption Systems) }\end{array}$ & $\begin{array}{l}\text { Material used, Yield strength, Ultimate strength, Damping force, Damping } \\
\text { coefficient, Loss factor, Equivalent stiffness, Yield shear force coefficient }\end{array}$ \\
\hline $\begin{array}{l}\text { Control Systems Details } \\
\text { (Additional Mass Systems) }\end{array}$ & $\begin{array}{l}\text { Supporting system, damper, Actuator, maximum stroke, Additional mass, } \\
\text { (Additional mass / Building mass) ratio, Maximum control force, } \\
\text { Maximum output force, Shape of tank, Water depth, Device working range } \\
\text { for winds, Huge input control. }\end{array}$ \\
\hline $\begin{array}{l}\text { Earthquake Response } \\
\text { Analysis Results }\end{array}$ & $\begin{array}{l}\text { Input level, Story drift, Ductility ratio, Acceleration at the top of the } \\
\text { building. }\end{array}$ \\
\hline $\begin{array}{l}\text { Response Decreasing } \\
\text { Ratio }\end{array}$ & $\begin{array}{l}\text { Earthquake (ductility, story drift), Wind (acceleration at the top of the } \\
\text { building) }\end{array}$ \\
\hline
\end{tabular}

\section{CHARACTERISTICS OF RESPONSE CONTROLLED BUILDINGS}

Fig. 1 shows the number of cases for every system applied according to the age. The horizontal age axis corresponds to the year of completion of the building. The ratio of buildings constructed using energy absorption systems and additional mass systems are almost the same before the Hanshin Awaji earthquake occurred in 1995. However, the use of energy absorption systems increased greatly after 1995. Also, energy absorption systems started to be applied for earthquake resistant retrofit of existing RC buildings. The number of cases that used energy absorption systems and hysteresis damping type devices (HD) increased every year. Buildings that used viscous damping type devices (VD), or HD and VD devices together, are increasing. 


\section{Building Use}

Fig.2 shows the building use in which response control systems are adopted. These systems are applied mostly to office buildings, cooperative housings and hotels. Energy absorption systems are applied particularly to office buildings and cooperative housings. Additional mass systems are mostly used in cases like high observatories, control towers and hotels where the aspect ratio (building height/ width) is high.

Energy absorption systems are used for earthquake resistant retrofit of buildings which are mainly buildings of lower heights such as schools and factories.

\section{Building Height}

Fig.3 shows the building height range against the number of cases for every system. Fig.4 shows the building height range against the proportion of the systems used.

Energy absorption systems, HD, VD are applied in a wide range from low to high rise buildings, $90 \%$ of the buildings are within heights lower than $120 \mathrm{~m}$. Additional mass systems like the passive type TMD, TLD are used in buildings with heights lower than 150m. And Active control types HMD, AMD are mostly adopted for high rise buildings with heights larger than $120 \mathrm{~m}$.

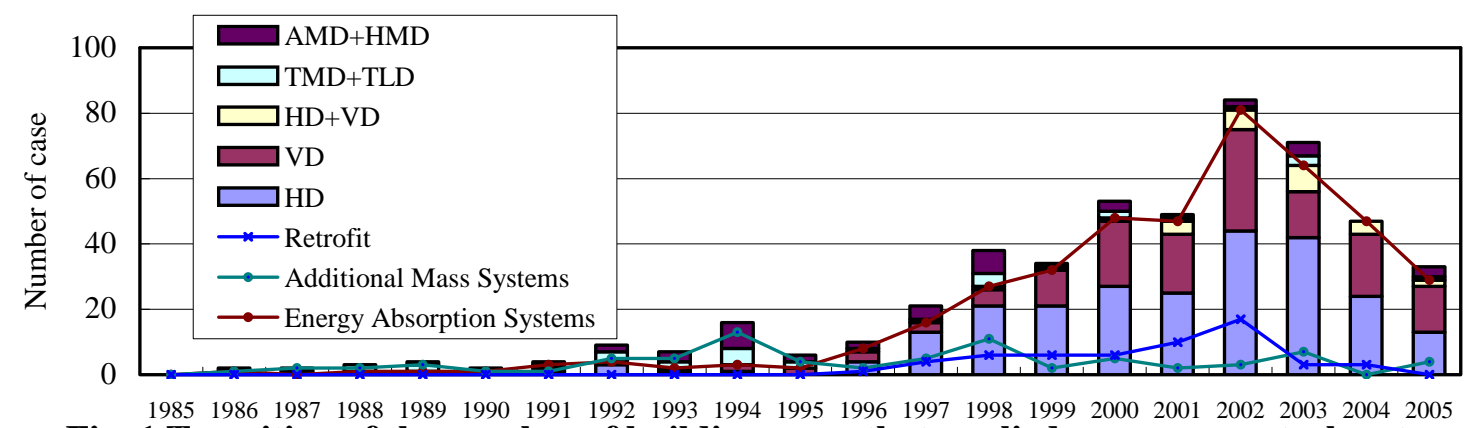

Fig. 1 Transition of the number of building cases that applied response control systems

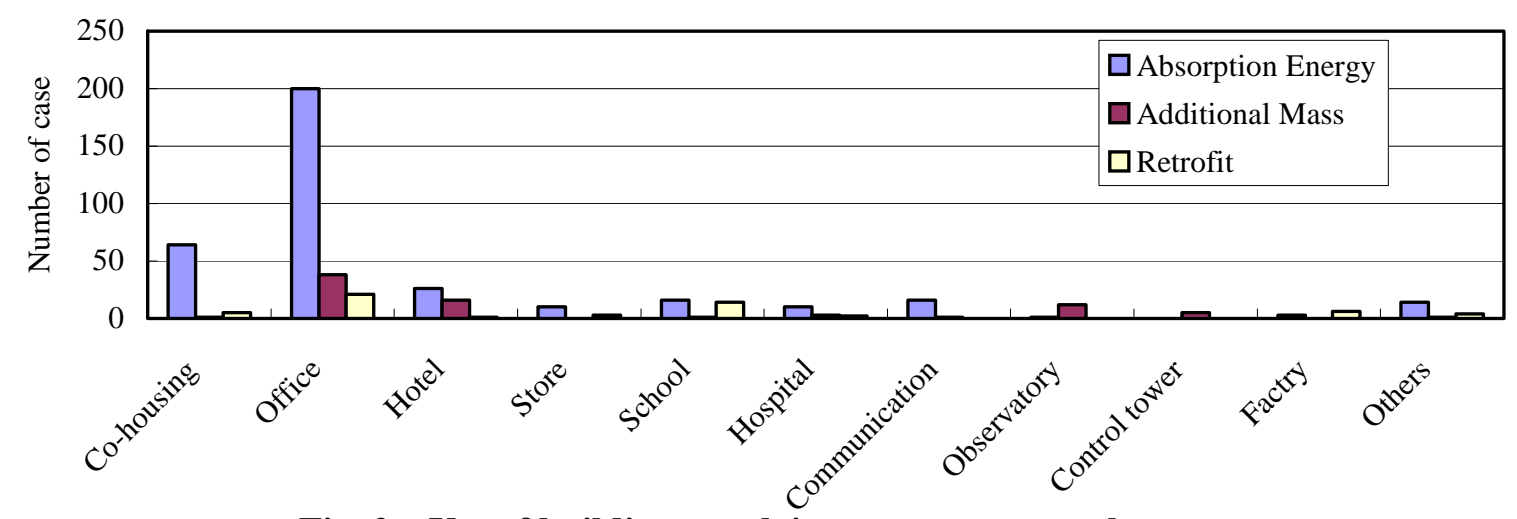

Fig. 2 Use of buildings applying response control systems

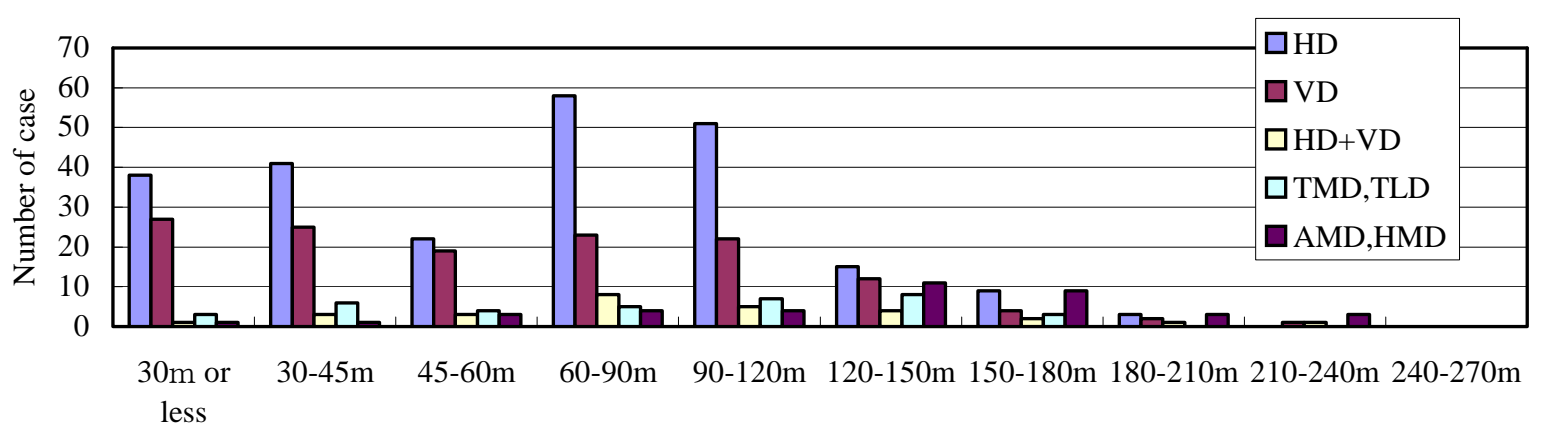

Fig. 3 Building height range against the number of building cases for each response control system 


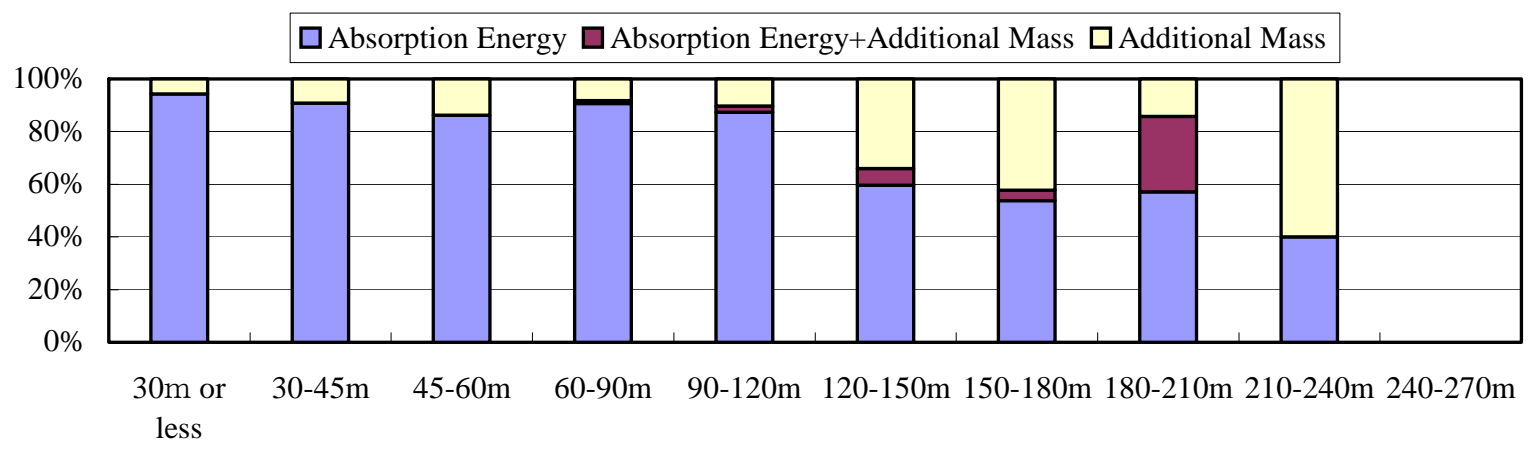

Fig. 4 Building height range against the proportion of the response control systems used

\section{Structural System and Building Period}

According to the building structural classification, there are the steel structure (S)and the reinforced concrete structure (RC) types. Fig.5 shows the building height and the first natural period relationship for these types. The solid lines in this figure represent the approximated methods $\mathrm{T}=0.03 \mathrm{H}$ for $\mathrm{S}$ type buildings and $\mathrm{T}=0.02 \mathrm{H}$ for $\mathrm{RC}$ type buildings. For $\mathrm{S}$ type buildings with heights in the range of $60 \mathrm{~m}$ or lower, it has been observed in many cases that the natural periods are longer in comparison with the ones from the approximated method. The reason is that the period is made longer intentionally in order to improve the response control effect. For the case of RC type buildings, the natural period is almost equal to the one calculated with the approximated method.

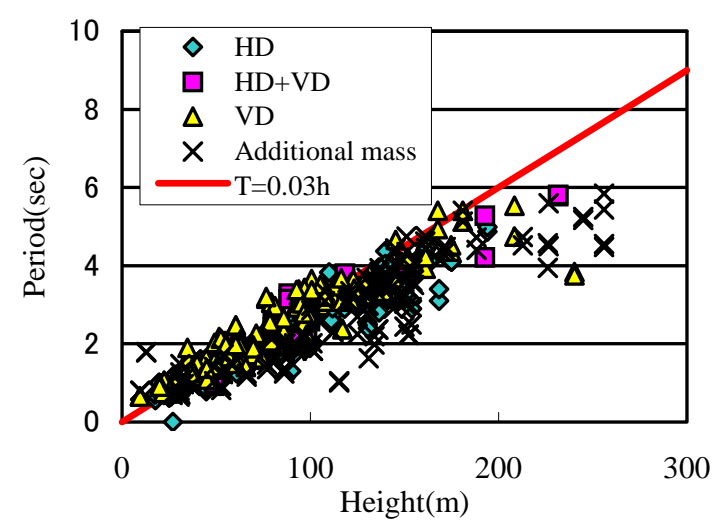

(a) $\mathrm{S}$ type buildings

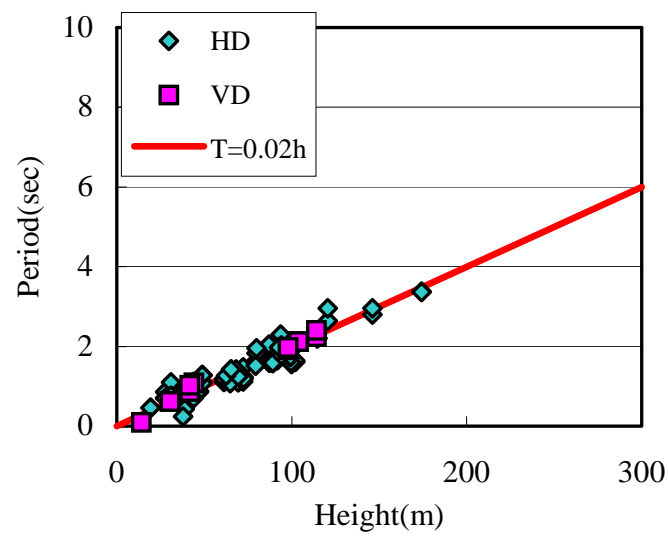

(b) RC type buildings

Fig. 5 Relation between building height and building natural period

\section{Building Period and Base shear Coefficient}

Fig.6 shows the relation between the building period and the base shear coefficient corresponding to the first stage design. The solid line in the figure represents the values of the soil type 2 from the Seismic Design Law 1981. It is possible to observe that most of the cases exceed the base shear of the Seismic Design Law 1981 for any of the energy absorption systems used.

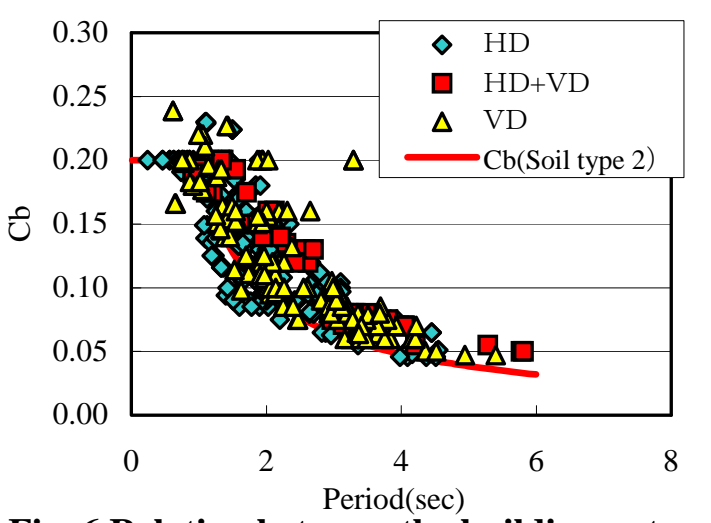

Fig. 6 Relation between the building natural period and the base shear coefficient 


\section{CHARACTERISTICS OF RESPONSE CONTROL SYSTEMS}

\section{Energy absorption Systems}

\section{Hysteresis Damping Type Device (HD)}

Hysteresis Damping Type Device makes the most of the metal's plastic strain energy absorption ability. It uses steel with low yielding point and extremely high plastic deformation ability. Fig.7 shows the number of cases that use HD. It includes mostly steels with yielding strength of $100 \mathrm{~N} / \mathrm{mm}^{2}$ to 225 $\mathrm{N} / \mathrm{mm}^{2}$.

\section{Viscous Damping Type Device (VD)}

Viscous Damping Type Device uses the shear resistance of a silicon type (high viscous fluid) in viscous wall dampers and viscous dampers. There are also oil dampers that utilize the resistance force of the fluid passing through a void in case of an emergency. And besides there are visco-elastic dampers that use the shear resistance force of a visco-elastic body like acrylic or a high damping rubber type. Fig. 7 shows also the number of cases that use VD.

It is possible to observe that the number of building cases that adopt oil dampers (OD) and damper walls (DW) is high and almost of the same proportion, while the number of building cases that use viscous dampers and visco-elastic dampers is half of the number of cases that use OD/DW.

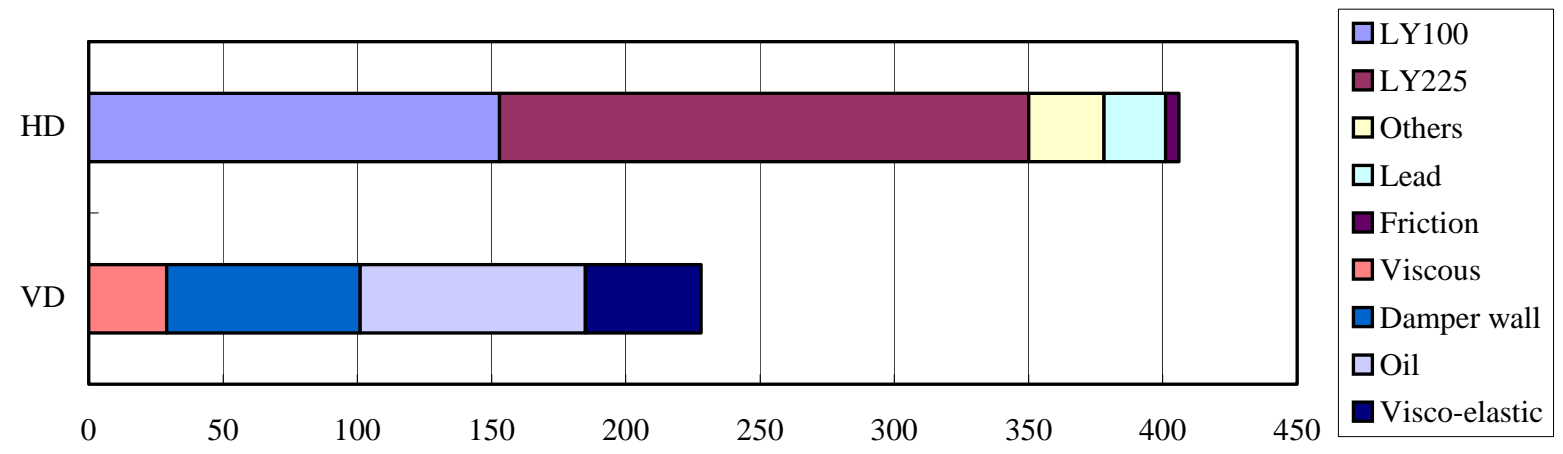

Fig. 7 Number of building cases that use HD and VD devices

\section{Installment Method}

Fig.8 shows the installation method of energy absorption systems that make the most of the building relative story displacement. Fig.9 shows the number of cases that use each installation method.

Hysteresis damping type devices (HD) are: Damper walls that use extra-low yielding point steel, Braces with buckling restrictions that show plastic hysteresis characteristics and stability for tension and compression forces.

Besides, there are Link systems that consist of damper panels made of steel plates with slits and sheet steel that uses extra-low yielding point steel which are installed using additional members like brace type and stud-column type, etc.

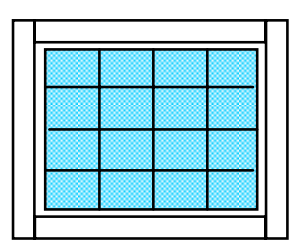

(a) Wall

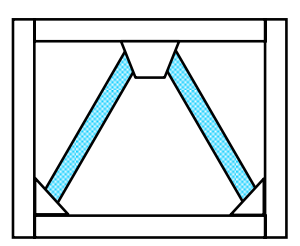

(b) Brace

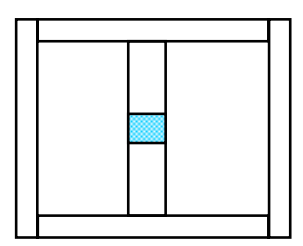

Stud

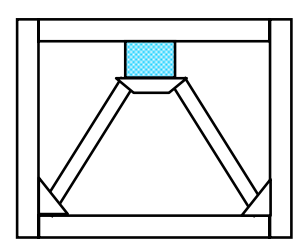

Brace

(c) Link 
Among the viscous damping type devices are: Viscous damper walls, visco-elastic damper brace types and oil damper brace types. Besides, there are link systems such as viscous dampers which are installed using additional members like brace type or stud-column type. About $50 \%$ of the devices applied are Brace systems. And the damper wall is the next mostly used.

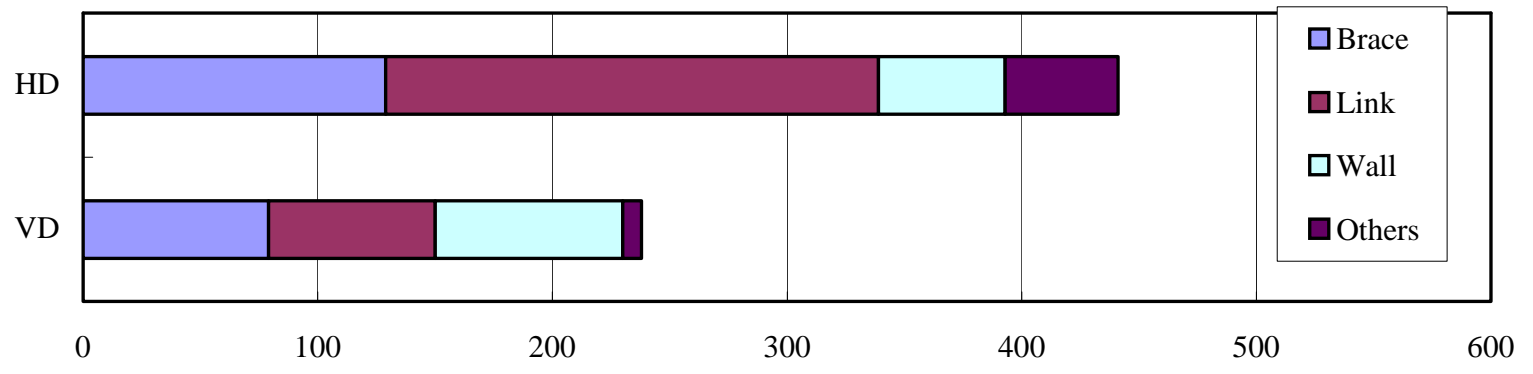

Fig. 9 Number of building cases that use each installation method

\section{Additional Mass Systems}

Additional mass system makes use of the motion of the vibration mass system added to the building. It absorbs the building vibration energy and decreases in this way the vibration response. There are two control systems: passive control and active control. Passive control systems like TMD (Tuned Mass Damper), where the additional mass vibration and the building vibration are tuned such that resonance occurs at the same frequency. And TLD (Tuned Liquid Damper) where the vessel liquid sloshing and the building vibration are tuned such that resonance occurs at the same frequency.

There are two Active Control systems: AMD (Active Mass Damper), and the HMD (Hybrid Mass Damper). AMD is the system where the additional mass without tuning or without period is controlled by the power machines of actuators based on the sensors measurement information. HMD controls the tuning resonance devices TMD with a machine power force smaller than AMD, and with a response reduction effect larger than TMD.

\section{Support System}

There are many kinds of support systems for additional masses like: the roller spring system, the pendulum system (including the multi pendulum system), laminated rubber isolator system (including the multi rubber isolator system), linear bearing and so on. Fig.10 shows the number of cases that use these systems. It is possible to observe that the pendulum system and the laminated rubber isolator system are mostly used as support systems.

\section{Control System}

The control systems used for AMD and HMD are oil pressure actuators, AC servo motor ball screw and linear motors. Fig. 11 shows the number of cases that applies these systems, in which is possible to observe that the servo motor ball screw is mostly used.

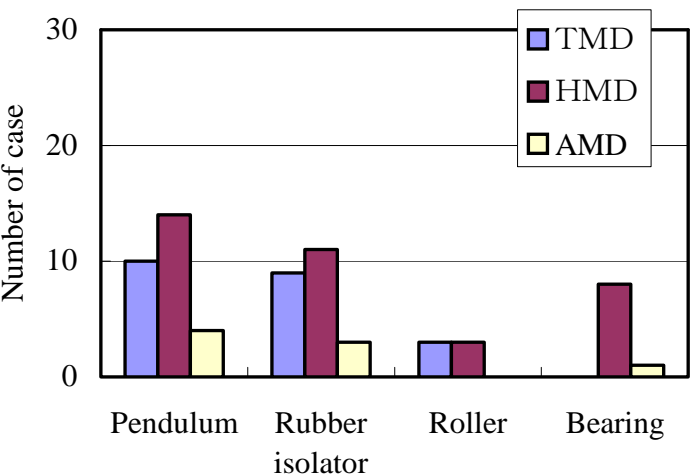

Fig. 10 Number of building cases that use each support system

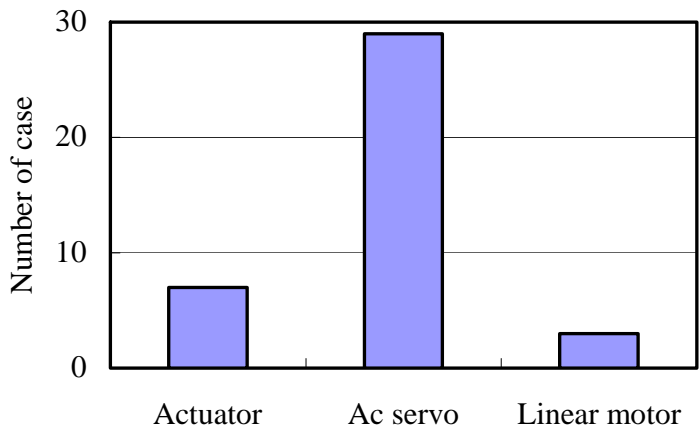

Fig. 11 Number of building cases that use each control system 


\section{CONTROL EFFECT IN THE BUILDING STRUCTURAL CONTROL RESPONSE}

\section{Energy Absorption Systems per unit area and Damping Force per Weight}

It is necessary to calculate the damping force of one response control device, the damping force for the total building weight and the damping force for the floor area where the device is installed (installed floor area) in order to evaluate the quantity of energy absorption systems to be set up.

\section{Response control-Device Damping Force}

The damping force for one response control device adopted corresponds to the yielding shear force for a hysteresis damping type device, to the limit load for the oil damper which is a viscous damping type device, to the damping force at the time assumed to occur the maximum velocity response for a viscous damper, to the damping force obtained from the maximum amplitude and the building first natural period for visco-elastic damper. Fig.12 shows the relation between the number of building cases and the damping force for one response control device. The values in this figure show the maximum values for response control devices. HD uses response control devices with values from less than $500 \mathrm{kN} /$ device to large response control devices with values larger than $3500 \mathrm{kN} /$ device. Small devices with $1500 \mathrm{kN}$ /device or less are mostly used in buildings. VD type oil dampers and viscous dampers with comparatively large damping forces of $500-2000 \mathrm{kN} /$ device, and VD visco elastic dampers with small damping forces of less than $1000 \mathrm{kN} /$ device are also quite used in buildings.

\section{Damping Force Per Weight of the Building}

The total damping force of a response control device in both directions $\mathrm{X}, \mathrm{Y}$ is the damping force average value for one device multiplied by the total number of devices set up. The damping force per building weight, obtained dividing this total damping force by the super structure building weight, is a little different from the actual value. Fig.13 shows the relation between the building height and the

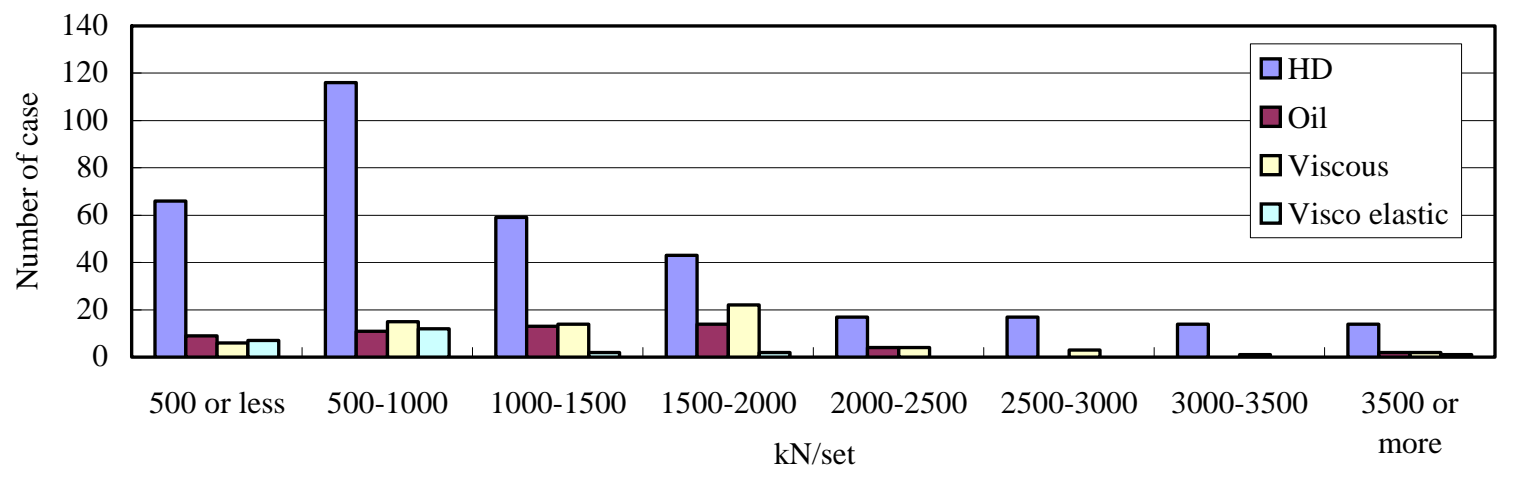

Fig. 12 Relation between the number of building cases and the damping force for one device

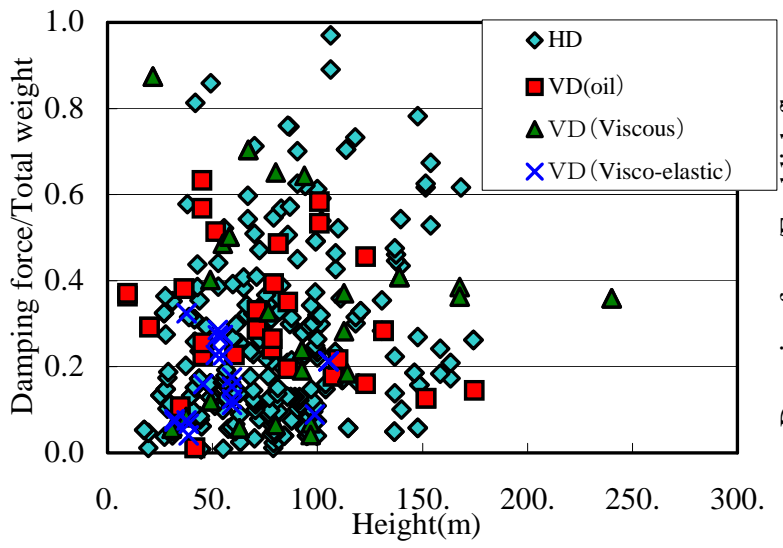

Fig. 13 Relation between the building height and the damping force per building weight

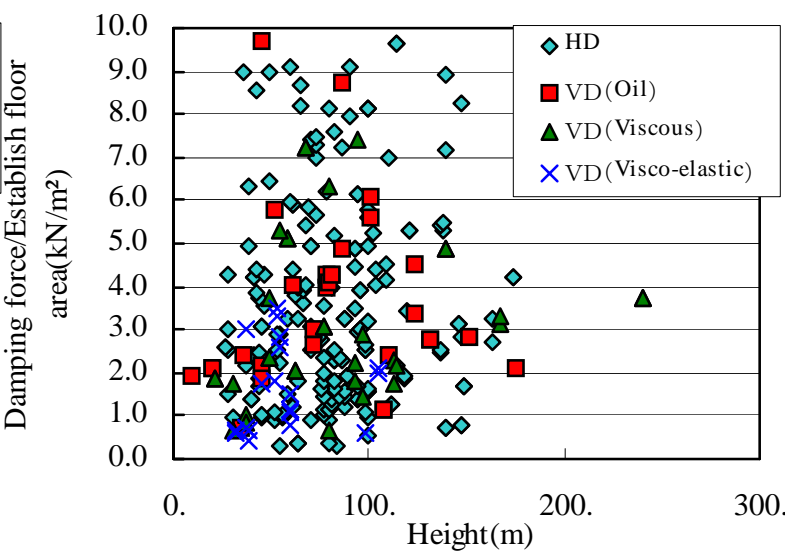

Fig. 14 Relation between the building height and the damping force per installed floor area 
damping force per building weight. The damping force per building weight is mostly distributed within the range of $0.05-0.5$ without depending on the height of the building. HD dampers and viscous dampers are concentrated within a wide range of $0.05-1.0$, oil dampers are concentrated within values that are less than 0.5 , and VD visco-elastic dampers are concentrated within values that are less than 0.3 .

\section{Damping Force per Installed Floor area}

The total installed floor area of a response control device in both directions $\mathrm{X}, \mathrm{Y}$ is the typical floor area multiplied by the number of floors where the response control devices are set up. The damping force of a response control device per installed floor area is the total damping force of the response control device mentioned above divided by the installed floor area. Fig.14 shows the relation between the building height and the response control device damping force per installed floor area. The response control device damping force per installed floor area is mostly distributed within a range that is less than $6.0 \mathrm{kN} / \mathrm{m}^{2}$ without depending on the height of the building. The damping force of the oil damper per installed floor area is larger than the already determined damping force per building weight. This is due to that oil dampers locations are concentrated at the middle or lower floors.

\section{Mass Ratio of Additional Mass Systems}

The ratio of the additional mass system weight and the building super structure weight shall be calculated in order to evaluate the amount of the additional mass systems installed. Fig. 15 shows the relation between the building natural period and the additional mass ratio. The additional mass ratio tends to be smaller as the natural period is longer. It is concentrated within the range of less than $1 \%$. Besides, the mass ratio of HMD, AMD is about $50 \%$ of TMD.

\section{Response Decreasing Effect in Response Control Buildings}

Response Decreasing Effect of Energy Absorption Systems When an Earthquake Occurs Fig.16(a) shows the relation between the decreasing rate of the ductility factor for a level 2 earthquake, obtained by the designers during the

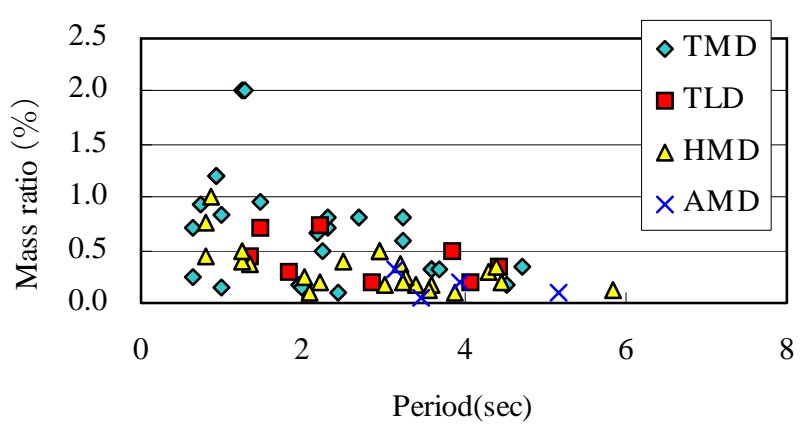

Fig. 15 Relation between the building natural period and the additional mass ratio

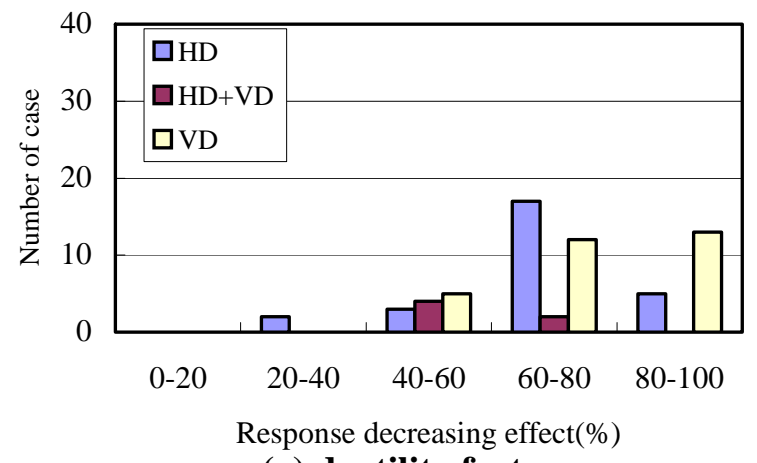

(a) ductility factor

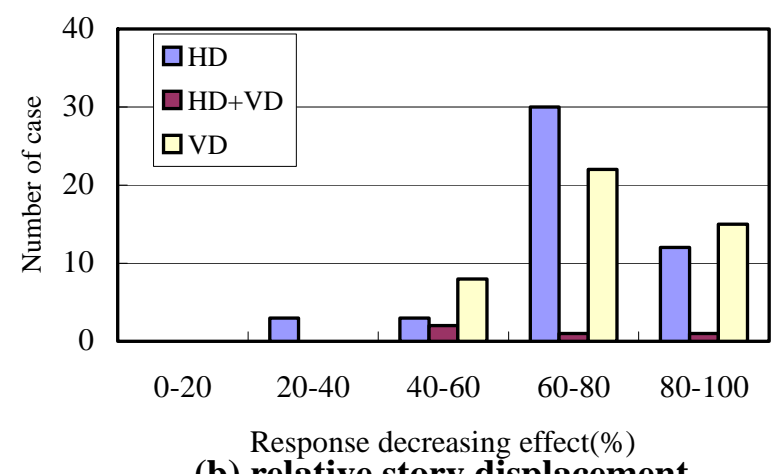

(b) relative story displacement

Fig. 16 Response decreasing effect of energy absorption systems for a level 2 earthquake

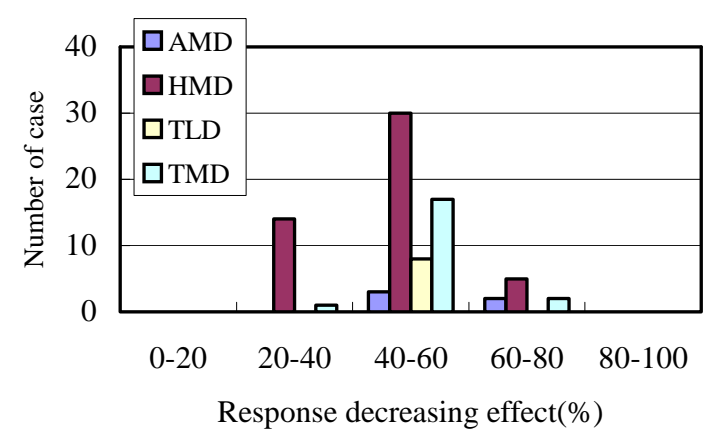

Fig. 17 Response decreasing effect of additional mass systems for strong winds 
building survey, and the number of building cases. Fig.16(b) shows the relation between the relative story displacement and the number of building cases. There are mostly decreasing factors of $60-80 \%$ for buildings that set up HD, and decreasing factors of $60-100 \%$ for buildings that set up VD.

\section{Additional Mass Systems Response decreasing Effect for Strong Winds}

Fig.17 shows the relation between the acceleration decreasing ratio and the number of building cases in which habitability for strong winds has been investigated for one-year return period. Decreasing ratios of $40-60 \%$ are mostly observed for buildings with additional mass systems installed, and decreasing ratios of $20-40 \%$ for active types HMD, AMD.

\section{COMPARISON OF THE RESPONSE CONTROL SYSTEMS STORING AND ABSORBING ENERGY AMOUNT}

\section{Calculation Method for the Storing and Absorbing Energy Amount}

The balance equation for the energy of response control structures is given by ${ }^{2)}$,

$$
{ }_{s} W_{e}+{ }_{s} W_{d}+{ }_{s} W_{p}+{ }_{D} W_{e}+{ }_{D} W_{d}+{ }_{D} W_{p}=E
$$

Where $S$ represents the frame structure, $D$ represents response control system. ${ }_{s} W_{e},{ }_{D} W_{e}$ denote the vibration energy (= kinetic energy + elastic strain energy), ${ }_{s} W_{d},{ }_{D} W_{d}$ represent the absorption energy due to damping, and ${ }_{s} W_{p},{ }_{D} W_{p}$ represent the plastic hysteresis energy.

The structure frame damping ${ }_{s} W_{d}$ can be switched to the right side when the structure frame behavior is elastic $\left({ }_{s} W_{p}=0\right)$. The energy balance equation for the energy absorption system can be written as follows when the vibration energy of the control member is so small that can be neglected $\left({ }_{D} W_{e}=0\right)$.

$$
{ }_{s} W_{e}+{ }_{D} W_{d}+{ }_{D} W_{p}=E-{ }_{s} W_{d}
$$

Similarly, the energy balance equation for additional mass systems is,

$$
{ }_{s} W_{e}+{ }_{D} W_{e}+{ }_{D} W_{d}=E-{ }_{s} W_{d}
$$

Furthermore, the energy balance equation for isolated structures is as follows considering that the super structure has a rigid body vibration $\left({ }_{s} W_{e}={ }_{s} W_{d}={ }_{s} W_{p}=0\right)$,

$$
{ }_{f} W_{e}+{ }_{s} W_{d}+{ }_{s} W_{p}=E
$$

Where, ${ }_{f} W_{e}$ denotes the elastic strain energy of the laminated rubber isolator, and ${ }_{s} W_{d},{ }_{s} W_{p}$ represent the energy absorption of viscous and hysteresis damping type dampers respectively.

In the case of energy absorption systems, the building response is controlled by the plastic hysteresis energy of the response control device ${ }_{D} W_{p}$ in the energy balance equation (2) for buildings using HD and the viscous damping energy of the response control device ${ }_{D} W_{d}$ for buildings using VD.

Similarly for buildings using additional mass systems the building response is controlled by the vibration energy of the additional mass ${ }_{D} W_{e}$ in equation (3). For seismic isolated structures the building response is controlled by the laminated rubber elastic strain energy ${ }_{f} W_{e}$ in equation (4).

The HD's ${ }_{D} W_{p}$, VD's ${ }_{D} W_{d}$, additional mass system's ${ }_{D} W_{e}$ and the isolated structure's ${ }_{f} W_{e}$ are converted into equivalent velocity values $V_{E}$ which are compared in order to evaluate the efficiency of every system.

Following is the equation to calculate the equivalent velocity ${ }_{D} V_{E P}$ corresponding to HD's ${ }_{D} W_{p}$,

$$
\begin{aligned}
{ }_{D} W_{d} & =\sum n_{1} \cdot \pi\left({ }_{D} C_{i} \frac{2 \pi}{T_{1}} \delta_{\max i}\right) \delta_{\max i} \\
& =\pi \cdot n_{1} \sum{ }_{D} F_{i} \cdot \delta_{\max i}
\end{aligned}
$$




$$
{ }_{D} V_{E d}=\sqrt{\frac{2{ }_{D} W_{d}}{M}}=\sqrt{\frac{2 \pi \cdot n_{1}}{M} \sum_{i=1}^{N}{ }_{D} F_{i} \cdot \delta_{\max i}}
$$

Where, ${ }_{D} Q_{y i}$ is the HD yielding shear force, $\delta_{\max i}$ is the maximum relative story displacement, ${ }_{D} \delta_{p i}(=4$ $\left.n_{1}\left(\delta_{\max i}-{ }_{D} \delta_{y i}\right) \approx 4 n_{1} \delta_{\max i}\right)$ is the HD accumulated plastic deformation, $M$ denotes the total mass of the super structure. $n_{1}$ is a coefficient that expresses the relation between the accumulated plastic deformation ${ }_{D} \delta_{p i}$ and maximum relative story displacement $\delta_{\max }$, it is also a value that represents the number of loops through the maximum displacement amplitude $\delta_{\max i}$ in the plastic hysteresis energy ${ }_{D} W_{p}$. Generally, a value greater than 2.0 is taken for control devices ${ }^{2}$.

The VD's ${ }_{D} W_{d}$ and the equivalent velocity ${ }_{D} V_{E d}$ are calculated as follows,

$$
\begin{aligned}
{ }_{D} W_{d} & =\sum n_{1} \cdot \pi\left({ }_{D} C_{i} \frac{2 \pi}{T_{1}} \delta_{\max i}\right) \delta_{\max i} \\
& =\pi \cdot n_{1} \sum_{D} F_{i} \cdot \delta_{\max i} \\
{ }_{D} V_{E d} & =\sqrt{\frac{2{ }_{D} W_{d}}{M}}=\sqrt{\frac{2 \pi \cdot n_{1}}{M} \sum_{i=1}^{N}{ }_{D} F_{i} \cdot \delta_{\max i}}
\end{aligned}
$$

Where, ${ }_{D} C_{i}$ is the viscous damping coefficient for $\mathrm{VD},{ }_{D} F_{i}$ is damping force for $\mathrm{VD}, T_{1}$ is the building first natural period.

The maximum vibration energy ${ }_{D} W_{e}$ stored by the additional mass (MD) and the equivalent velocity ${ }_{D} V_{E e}$ are calculated as follows,

$$
\begin{aligned}
& { }_{D} W_{e}=\frac{1}{2} k_{D} \cdot_{D} \delta_{\max }^{2}=\frac{1}{2}\left(\frac{2 \pi}{T_{D}}\right)^{2} m_{D} \cdot_{D} \delta_{\max }^{2} \\
& { }_{D} V_{E e}=\sqrt{\frac{2{ }_{D} W_{e}}{M}}=\frac{2 \pi}{T_{D}} \sqrt{\frac{m_{D}}{M}}{ }_{D} \delta_{\max }
\end{aligned}
$$

Here, $T_{D}$ is the MD natural period, $k_{D}$ is the MD horizontal spring constant, $m_{D}$ is MD's mass, ${ }_{D} \delta_{\max }$ is the MD critical deformation.

Besides, the maximum vibration energy ${ }_{f} W_{e}$ stored by the isolated structure's laminated rubber and the equivalent velocity ${ }_{f} V_{E e}$ are calculated as follows,

$$
\begin{aligned}
& { }_{f} W_{e}=\frac{1}{2} k_{f} \cdot f \delta_{\max }^{2}=\frac{1}{2}\left(\frac{2 \pi}{T_{f}}\right)^{2} M \cdot{ }_{f} \delta_{\max }^{2} \\
& { }_{f} V_{E e}=\sqrt{\frac{2 W_{e}}{M}}=2 \pi \frac{f}{T_{\max }}
\end{aligned}
$$

Where, $T_{f}$ is the isolator period corresponding only to the laminated rubber isolators, $k_{f}$ is the laminated rubber horizontal spring constant, ${ }_{f} \delta_{\max }$ is the laminated rubber critical deformation.

\section{Equivalent Velocity for the Storing and Absorbing Energy Amount}

\section{Equivalent Velocity for the absorbing energy amount of the energy absorption systems}

The equivalent velocities for the absorbing energy amounts of HD and VD are calculated replacing the total damping force values calculated in Section 6 of HD's ${ }_{D} Q_{y i}$ and VD's ${ }_{D} F_{i}$ and the typical floor maximum story displacement corresponding to a story drift of 1/100 in equations (5) and (6). Fig.18 shows the relation between the natural period of buildings using energy absorption systems and the equivalent velocity for the absorbing energy amount. The dispersion range of the equivalent velocity for HD is larger in comparison with VD, however both are concentrated within a range that is less than $V_{E}=2.0 \mathrm{~m} / \mathrm{s}$. Therefore, control members are set up with equivalent velocities almost constant without concerning about the building period. 


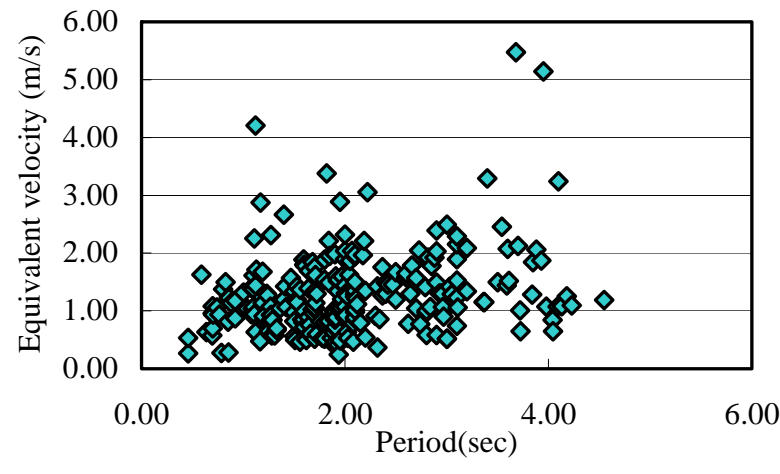

(a) Hysteresis damping types

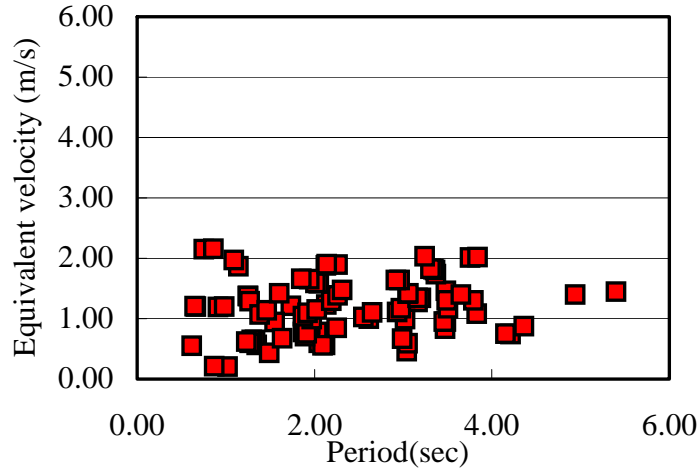

(b) Viscous damping types

Fig. 18 Equivalent velocity for the absorbing energy amount of energy absorption systems

Equivalent Velocity for the storing energy amount of the additional mass systems

The equivalent velocity for the storing energy amount is calculated replacing the building first natural period as the natural period of MD and, the MD additional mass ratio and the critical deformation in equation (7). Fig.19 shows the relation between the natural period of the building using additional mass systems and equivalent velocity for the storing energy amount. There is a tendency that the equivalent velocity is smaller as the building period is longer for both cases, the passive type (TMD), and the active type (HMD, AMD). Besides both are concentrated within a range that is less than $V_{E}=0.2 \mathrm{~m} / \mathrm{s}$.

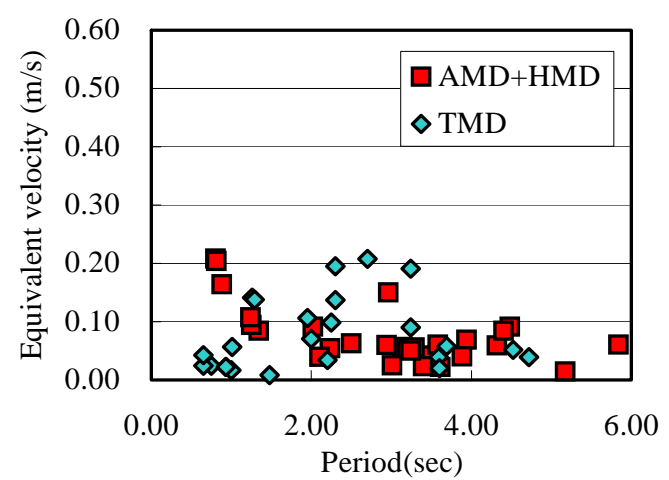

Fig. 19 Equivalent velocity for the storing energy amount of additional mass systems

\section{Equivalent Velocity for the storing energy amount of Seismic Isolated Structures}

The equivalent velocity for the storing energy amount of seismic isolated structures is calculated replacing the isolated building period of only the laminated rubber $T_{f}$, and the critical deformation of the laminated rubber $\delta_{\max }$ in equation (8). The equivalent velocity value for the storing energy amount is approximately constant as the isolated building period is longer and there is a tendency to assume the critical deformation to be larger for isolated structures. $\delta_{\max }=0.5,0.8 \mathrm{~m}$, when $T_{f}=3.0,4.0 \mathrm{~s}$ and the values of $V_{E}$ are distributed within a range of ${ }_{f} V_{E e}=0.9-1.2 \mathrm{~m} / \mathrm{s}$.

\section{Comparison and Investigation of the Equivalent Velocity for Storing and Absorbing Energy Amount}

This report estimates the upper limit of the storing and absorbing amount as the equivalent velocity for the storing and absorbing energy amount is calculated using the maximum damping force and the critical deformation. The equivalent velocity value needed for storing and absorbing energy amount is $V_{E}=0.5-1.5 \mathrm{~m} / \mathrm{s}$ which is the goal for energy absorption systems and seismic isolated structures for the case of control response when a large earthquake occurs. The equivalent velocity for mass additional systems used for wind is less than ${ }_{D} V_{E e}=0.2 \mathrm{~m} / \mathrm{s}$, therefore the energy storing amount is not enough to expect control effect for the case of a large earthquake. 


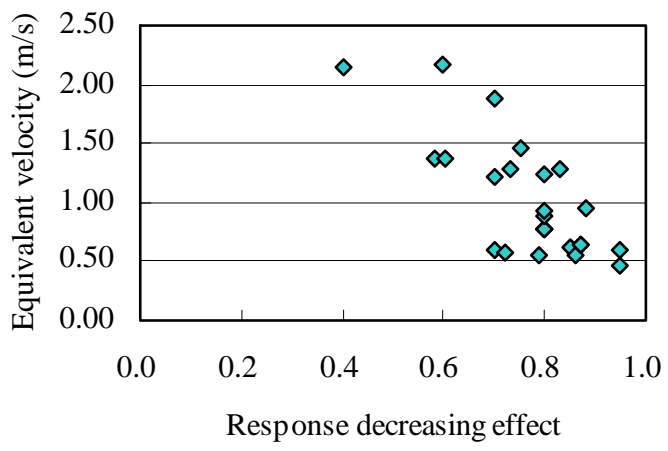

(a) Hysteresis damping types

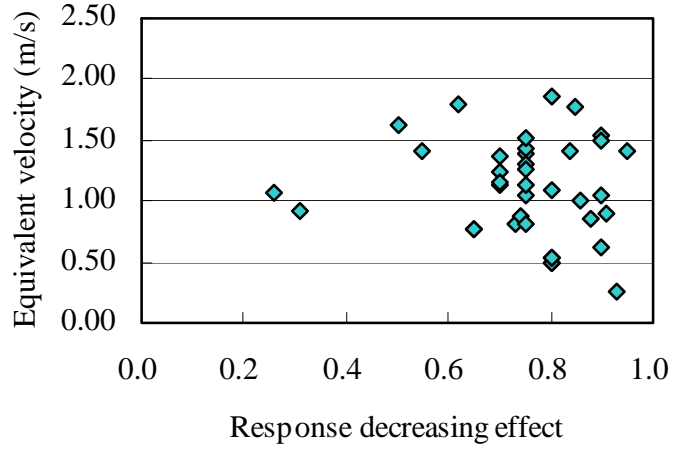

(b) Viscous damping types

Fig. 20 Relation between the response decreasing effectand the equivalent velocity of energy absorption systems

\section{Equivalent Velocity for Storing and Absorbing Energy Amount and Response Decreasing Effect}

The relation between the response decreasing effect assumed by the designers as shown in section 6.3, and the equivalent velocity for storing and absorbing energy amount is investigated in this report. Figs. 20 and 21 show the relation between the absorbing energy systems equivalent velocity and the response decreasing effect, and between the additional mass systems equivalent velocity and the response decreasing effect respectively. In spite of the wide dispersion, it is possible to observe a tendency where the response-decreasing ratio becomes smaller as the equivalent velocity becomes larger. Thus it is recognized a correlation between the equivalent velocity $V_{E}$ and the response decreasing ratio estimated by the designer. Therefore it is possible to say that the equivalent velocity is like an indicator for the response control capability.

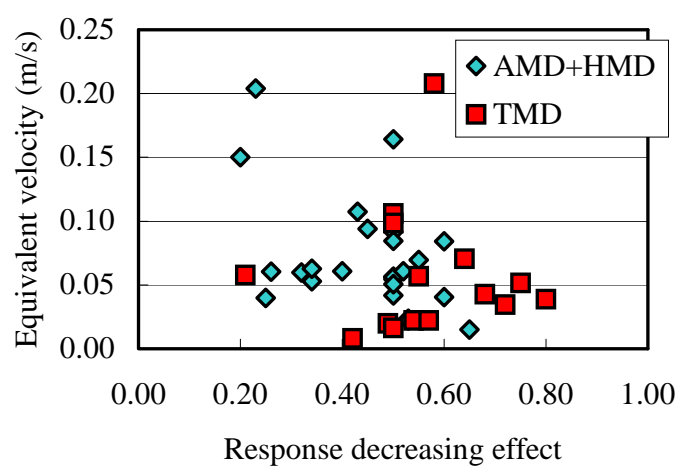

Fig. 21 Relation between the response decreasing effect and the equivalent velocity of additional mass systems

\section{CONCLUSION}

The present condition of buildings applying response control systems is introduced in this report using the 494 cases from the Japan database of response control buildings, energy absorption systems and additional mass systems.

The Hanshin Awaji earthquake in 1995 has been a turning point for the application of response control buildings. The number of buildings adopting energy absorption systems for large earthquakes increased rapidly, and also the application of response control retrofit techniques started to be used in the earthquake resistant strengthening of existing RC buildings. The equivalent velocity for storing and absorbing energy amount $V_{E}$ is proposed as an indicator to estimate the response control capability of the response control systems. From the buildings investigated: it has been found that $V_{E}=0.5-$ $1.5 \mathrm{~m} / \mathrm{s}$ for the case of response control buildings for earthquakes and, $V_{E}=0.2 \mathrm{~m} / \mathrm{s}$ or less for the case of response control buildings for strong winds. It is clearly shown the response decreasing ratio expected by the designers when using response control devices and also that the VE is equivalent to the earthquake or strong wind input energies. 


\section{ACKNOWLEDGEMENT}

This report is based on the results of the investigation performed for the response-controlled buildings by the Japan Structural Engineer and Consultant Association (JSCA). The authors wish to express their sincere thanks and appreciation to the many JSCA members that supported them during the data collection.

JSCA Response Control Committee;

Chairman : Haruyuki KITAMURA

Vice Chairmen : Masaru ITO/ Mistuo SAKAMOTO

Members : Hiroyuki AOKI/ Mizumasa Uchikoshi/ Shoji KATSUTA/

Yoshihisa KITAMURA/ Masahito KIBAYASHI/ Yasushi KUROKAWA/

Tatsuya KOIZUMI/ Toshiyuki SUEOKA/ Osamu TAKAHASHI/

Toru TAKEUCHI/ Toshifumi NINOMIYA

\section{REFERENCES}

1) Japan Structural Engineer and Consultant Association: JSCA Recommendation for Design of Structural Controlled buildings, shokokusha, Dec 2002

2) Hiroshi AKIYAMA: Energy balanced earthquake resistant design for Buildings, Gihodoshuppan, Nov 1999

3) Architectural Institute of Japan: Recommendation for the Design of Base Isolated Buildings( $3^{\text {nd }}$ Edition), Sept 2001

4) H. KITAMURA, Y. KITAMURA, M. ITO, M. SAKAMOTO: Analysis of the Present Situation of Response Control Systems in Japan Based on the Survey of Applied Buildings, AIJ J. Technol. Des. No. 18, 55-60, Dec., 2003

(Submitted: March 31, 2004)

(Accepted: June 22, 2004)

Copyright JAEE 